This item was submitted to Loughborough's Research Repository by the author.

Items in Figshare are protected by copyright, with all rights reserved, unless otherwise indicated.

\title{
Real-time monitoring of exhaled volatiles using atmospheric pressure chemical ionization on a compact mass spectrometer
}

\author{
PLEASE CITE THE PUBLISHED VERSION
}

http://dx.doi.org/10.4155/bio-2016-0045

\section{PUBLISHER}

(C) Future Science Ltd

\section{VERSION}

AM (Accepted Manuscript)

\section{PUBLISHER STATEMENT}

This work is made available according to the conditions of the Creative Commons Attribution-NonCommercialNoDerivatives 4.0 International (CC BY-NC-ND 4.0) licence. Full details of this licence are available at: https://creativecommons.org/licenses/by-nc-nd/4.0/

\section{LICENCE}

CC BY-NC-ND 4.0

\section{REPOSITORY RECORD}

Heaney, Liam, Dorota Ruszkiewicz, Kayleigh L. Arthur, Andria Hadjithekli, Clive Aldcroft, Martin Lindley, Paul Thomas, Matthew Turner, and Jim Reynolds. 2019. "Real-time Monitoring of Exhaled Volatiles Using Atmospheric Pressure Chemical Ionization on a Compact Mass Spectrometer". figshare. https://hdl.handle.net/2134/22012. 
Title: Real-time monitoring of exhaled volatiles using atmospheric pressure chemical ionization on a compact mass spectrometer

Authors: Liam M Heaney, ${ }^{1,2,3}$ Dorota M Ruszkiewicz, ${ }^{1}$ Kayleigh L Arthur, ${ }^{1}$ Andria Hadjithekli, ${ }^{1}$ Clive Aldcroft, ${ }^{4}$ Martin R Lindley, ${ }^{2}$ CL Paul Thomas, ${ }^{1}$ Matthew A Turner, ${ }^{1 \star}$ James C Reynolds ${ }^{1 *}$

* MA Turner and JC Reynolds contributed equally to this manuscript

\section{Affiliations:}

${ }^{1}$ Centre for Analytical Science, Department of Chemistry, Loughborough University, Epinal Way, Loughborough, Leicestershire LE11 3TU, UK

${ }^{2}$ School of Sport, Exercise and Health Sciences, Loughborough University, Epinal Way, Loughborough, Leicestershire LE11 3TU, UK

${ }^{3}$ Department of Cardiovascular Sciences and NIHR Leicester Cardiovascular Biomedical Research Unit, University of Leicester, Glenfield Hospital, Leicester LE3 9QP, UK

${ }^{4}$ Advion UK Ltd, Edinburgh Way, Harlow CM20 2NQ, UK 


\section{Corresponding Author(s):}

Dr James C Reynolds, Centre for Analytical Science, Department of Chemistry, Loughborough University, Epinal Way, Loughborough, Leicestershire LE11 3TU, UK.

J.C.Reyonlds@Lboro.ac.uk; 01509222590

Dr Matthew A Turner, Centre for Analytical Science, Department of Chemistry, Loughborough University, Epinal Way, Loughborough, Leicestershire LE11 3TU, UK.

M.A.Turner@Lboro.ac.uk; 01509222590

Keywords: exhaled breath; atmospheric pressure chemical ionization; mass spectrometry; volatile organic compounds; metabolism 


\section{Introduction}

The development of rapid, non-invasive methods of screening for volatile organic compounds (VOCs) in breath has potential in a number of different areas. Areas of interest include point-of-care medical diagnostics, for example determining narcotic and alcohol intoxication [1], and food chemistry, as a method of monitoring aroma compounds and flavor release [2]. There are a number of different technologies available for these applications including ion mobility spectrometry [3], chemical sensors (e.g. electronic nose) [4] and spectroscopic methods such as Fourier transform infrared spectroscopy [5]. All of these technologies have the potential to be easily miniaturized and work in the field or point-of-care settings. However, limitations exist in that they may be specific to a particular group of target compounds or suffer background interferences through low resolution.

Mass spectrometry (MS) has the potential to obtain higher resolution data and enables straightforward identification of a compound by its mass to charge ratio $(\mathrm{m} / \mathrm{z})$. Gas chromatography-MS (GC-MS) has for many years been the technique of choice for breath analysis [6]. GC-MS can offer high chromatographic resolution and is readily coupled to pre-concentration techniques such as thermal desorption [7] (TD) or needle trap devices [8] which enable trace level VOCs in breath to be focused to detectable levels prior to analysis. Trapping on adsorbent tubes or storing samples in Tedlar bags allows samples to be collected at a remote location and later returned to the laboratory for analysis. Furthermore, the availability of GC compound libraries aid in the identification of VOCs present in breath samples. However this approach has its limitations, due to the inherent complexity of breath samples the chromatographic separation often requires long run times (30-60 min) making the technique ill-suited to high-throughput screening of large numbers of individuals. In 
addition, subtle chemical changes may occur during transport and/or storage time [9] and thus some information may be lost. Moreover, the equipment required for GCMS tends to be large, bulky and laboratory based that requires operation by specialist users.

The limitations of GC-MS have been partly resolved with the development of techniques such as proton transfer reaction-MS [10] and selected ion flow tube-MS (SIFT-MS) [11] for breath analysis. These approaches are capable of monitoring highly volatile species in breath in real-time, providing immediate diagnostic data with sub part per billion levels of sensitivity without the requirement for preconcentration procedures. SIFT-MS, in particular, has successfully demonstrated quantitative potential for breath analysis as single reactant ion species can be selected, thus simplifying the ion chemistry in the source. This has been employed for a range of different compounds in breath such as acetaldehyde, ammonia and isoprene $[12,13]$. Although more compact versions of these instruments have been developed, they remain heavy and not suited to transportation between laboratories and/or into the field.

Interfacing of exhaled breath sampling to MS using ambient ionization techniques such as extractive electrospray ionization [14-18], atmospheric pressure chemical ionization (APCI-MS) [19-21] and glow discharge [22] has also been accomplished. These approaches can be readily interfaced to mass spectrometers with atmospheric pressure ionization sources to allow analysis of volatiles. APCI-MS has proven very effective in determining volatile species, notably being used to detect aroma compounds released from food while eating [19-21]. This work led to the development of the MS-nose interface where a coaxial Venturi interface was used to produce a commercial volatile analysis source [23]. Outside of food analysis, 
on-line breath analysis using APCI-MS has been shown to be a sensitive method for determining narcotics in breath [24]. However, potential use of these equipment in the field is limited due to their size, cost and the requirement for climate controlled laboratories and expert users.

In recent years there has been interest in smaller, portable mass spectrometers. These instruments, albeit with some reduction in sensitivity of larger laboratory based mass spectrometers, have a far smaller footprint and lower cost while maintaining most of their functionality. This reduction in size potentially comes at the cost of a reduction in the $\mathrm{m} / \mathrm{z}$ scan range of the instruments. However, these losses usually occur in the higher $\mathrm{m} / \mathrm{z}$ regions and, therefore, do not affect the application of breath analysis to a great extent. Setup and running times are reduced in comparison to full-sized instrumentation, affording their use as mobile instrumentation. Recently, a number of instruments have been commercially released and have been demonstrated for a number of different applications including on-line flow chemistry [25] and phytochemical screening [26].

Here we demonstrate the coupling of exhaled breath analysis to an Advion Expression compact mass spectrometer (CMS) using an in-house designed and custom manufactured Venturi jet pump interface. Previous reports have evaluated the suitability of instrumental development through an induced fluctuation in a breath metabolite $[27,28]$. Therefore, we asked participants to ingest a commercially available peppermint oil capsule allowing subsequent release of VOCs for measurement in the breath. The emanation and elimination of menthone was monitored, and an established GC-MS method was employed for comparison. The aims of this preliminary communication were to demonstrate that versatile, low-cost and fieldable instrumentation can, with a simple modification, be used to monitor 
volatile compounds in the breath, and to show the potential of portable mass spectrometers for high sensitivity on-line breath analysis at the point-of-care. 


\section{Methods \& materials/Experimental}

\section{Instrumentation}

A full-face breathing mask (Resmed, Abingdon, UK) fitted with a one-way, nonrebreathable valve (Clement Clarke, Harlow, UK) was interfaced into the APCI source gas line of an Advion Expression CMS using an in-house constructed Venturi jet pump (Albrook Engineering, Loughborough UK) (Figure 1). The mask was connected to the Venturi pump using a $60 \mathrm{~cm}$ length of 1/8" O.D. 1/16" I.D PTFE tubing and the pump and tubing assembly was heated to $100{ }^{\circ} \mathrm{C}$ using a thermostatically controlled rope heater (Omega, Manchester, UK). The jet pump emitter consisted of a laser drilled glass lens (Bird Precision, Waltham, MA, USA, PN: RB-24010-.008) with an orifice size of $203 \mu \mathrm{m}$. The pump throat involved a 4 $\mathrm{mm}$ diameter narrowing to a $1.5 \mathrm{~mm}$ tube. The instrument was operated in positive ionization mode for all experiments. The air supply to the mask passed through a Balston DX, BX and $\mathrm{Cl}$ triple filter system to remove particulate and hydrocarbon interferences. The pre-conditioned air was supplied to the mask at $20 \mathrm{~L} / \mathrm{min}$ in order to provide adequate air flow for participants to ventilate comfortably. The APCI gas was set at $4 \mathrm{~L} / \mathrm{min}$ which gave a measured suction from the mask of $260 \mathrm{~mL} / \mathrm{min}$. The transport time from the mask to the ion source using this system was $<1 \mathrm{~s}$. Breath profiles were monitored both with the mass spectrometer and with a pressure transducer system [29]. The CMS ion source parameters were optimized using a menthol vapor source prior to analysis and the optimized conditions were as follows: capillary temperature $250^{\circ} \mathrm{C}$, capillary voltage $42 \mathrm{~V}$, source voltage $15 \mathrm{~V}$, APCl gas temperature $40^{\circ} \mathrm{C}$, corona discharge voltage $5 \mathrm{kV}$. All spectra were acquired over a range between $\mathrm{m} / \mathrm{z} 30-300$ at a scan rate of 1 scan per $300 \mathrm{~ms}$. The Expression 
CMS gives a resolving power of 0.5 to $0.7 \mathrm{~m} / \mathrm{z}$ units (FWHM) at $1000 \mathrm{~m} / \mathrm{z}$ units $/ \mathrm{s}$ over the acquisition range.

\section{Sampling}

Sixteen healthy volunteers were recruited for this study ( 7 male and 9 female over an age range from 22 to 53 years). All procedures were approved by the local ethical advisory board and participants provided written informed consent prior to the initiation of the study. All study protocols complied with the Declaration of Helsinki.

Prior to sampling, breath masks were disinfected using Milton solution followed by overnight conditioning in a vacuum oven at $50^{\circ} \mathrm{C}$. Each individual reused a single breath mask to ensure no transfer of infectious material or cross contamination between participants occurred. The participant was asked to breathe at a normal rate and depth and a 2 min equilibration time was performed prior to data acquisition. This familiarization allowed for any abnormal breathing patterns to subside and laboratory air contaminations to clear the system. Sample data points were collected for 3 min during which mass spectral data and pressure transducer breath profiles were acquired. Each participant was asked to arrive to the laboratory during the morning after an overnight fast and provided a blank breath sample (0 min) before ingesting a commercially available $200 \mathrm{mg}$ peppermint oil capsule (Boots, Nottingham, UK). Subsequent breath samples were recorded at 60, 120, 240 and 360 min post-ingestion (study 1). Additionally, an extended experiment was performed where breath samples were taken at 0, 180, 240, 360, 480 and 600 min ( $n=4)$ using 1 female and 3 male participants from the original study with ages ranging between 26 and 36 years (study 2). 
Finally, continuous real-time monitoring was conducted by a single participant. The individual exhaled at a normal depth and rate into the mask for 20 min postingestion of a peppermint oil capsule and data was continuously acquired (study 3).

\section{Statistical analyses}

Statistical analyses were performed using IBM SPSS Statistics (v22, IBM Corp., Armonk, NY, USA). Wilcoxon signed rank tests were performed to assess the changes in intensity of the exhaled ion $\mathrm{m} / \mathrm{z} 137$ and 155 (as ions of menthone) over time in comparison to baseline $(0 \mathrm{~min})$ measurements. All $p$ values described in this manuscript refer to their Bonferroni adjusted values for multiple comparisons. An adjusted $p$ value of $<0.05$ was deemed as statistically significant.

\section{Comparison with GC-MS}

Prior to commencement of participant sampling, a pilot experiment was conducted in order to estimate the potential levels of menthone in exhaled breath using a previously validated method [29]. Exhaled VOCs were collected from $2 \mathrm{~L}$ of breath prior to and at $73,174,415$ and 600 min post-ingestion of the peppermint oil capsule. Samples were collected on a dual-bed TD tube (Tenax:Carbograph TD, Markes Int., UK) and analyzed using thermal desorption (Unity 2, Markes Int., UK)gas chromatography (Agilent 7890, Wokingham, UK)-mass spectrometry (Agilent 5977A quadrupole mass spectrometer, Wokingham, UK) (TD-GC-MS) (study 4). Sample chromatograms were processed for the presence and intensity of $\mathrm{m} / \mathrm{z} 112$ (base peak of menthone for electron ionization) and an elimination curve was created. Levels of menthone and the period of wash out for these from the human 
biological system were assessed. Standard calibration analyses for menthone (Sigma-Aldrich, Gillingham, UK) were performed and quantitative values were obtained for each sample time point. 


\section{Results \& discussion}

\section{Accumulation and washout (Study 1 and 2)}

Breath samples taken from participants at 0 min were all shown to contain the $[\mathrm{M}+\mathrm{H}]^{+}$ion of acetone at $\mathrm{m} / \mathrm{z} 59$ as the base peak. In addition to the acetone monomer, a water cluster of acetone [acetone $\left.+\mathrm{H}_{2} \mathrm{O}+\mathrm{H}\right]^{+}$and proton-bound dimer $[2 \text { acetone }+\mathrm{H}]^{+}$were observed at $\mathrm{m} / \mathrm{z} 77$ and 117, respectively (Figure 2). The presence of acetone in the sample was expected since acetone is a major breath metabolite [30]. The concentration of acetone observed in the breath can be affected by a range of different factors such as diet, fasting and clinical state, and there been a wide range of studies conducted which have measured breath acetone. Smith et al. reported concentrations between 200 to 600 parts per billion by volume (ppbv) in healthy individuals following consumption of a liquid protein-calorie meal after a $12 \mathrm{hr}$ fast [31]. Clinical factors such as diabetes can result in elevated acetone levels, and a study by Wang et al. showed that breath acetone levels in type 1 diabetic patients were significantly higher than in healthy volunteers (2.19 versus $0.48 \mathrm{ppm}$ in diabetics and healthy controls, respectively) [32]. Ions relating to acetone were detectable from a single breath in all of the healthy participants tested in this study demonstrating sensitivity in the ppbv range.

The breathing profile of each participant could be clearly observed in the total ion trace (Figure 3), where each peak demonstrated an increase in ion counts at the onset of exhalation, a plateau during steady-state exhalation and a reduced ion count at the cessation of exhalation and beginning of inhalation. This breathing profile followed an identical pattern to that seen in the pressure trace measured from the breathing mask (Figure 4). 
Three notable peaks were additionally detected in the breath post-ingestion, with $m / z$ values of 81,137 and 155 (Figure 5). The peak observed at $m / z 155$ corresponds to the $[\mathrm{M}+\mathrm{H}]^{+}$ion of menthone, a major component of peppermint oil. The most intense of the peaks resulting from peppermint oil dosing was at $m / z 137$. This ion is a known diagnostic fragment ion for oxygenated terpenes and can arise from a number of different sources such as loss of water from the protonated menthone or protonation of monoterpene hydrocarbons, such as $\alpha$ - and $\beta$-pinene [33]. The identity of the $\mathrm{m} / \mathrm{z} 81$ peak is $\left[\mathrm{C}_{6} \mathrm{H}_{8}+\mathrm{H}\right]^{+}$which has shown to be a common ion from monoterpene fragmentation [34]. Analysis of a 1:100 dilution of a menthone standard in water by APCI-MS demonstrated that the $\mathrm{m} / \mathrm{z} 137$ ion is one of the main peaks in the mass spectrum (Figure S1), suggesting that a potential source of the $\mathrm{m} / \mathrm{z} 137$ ion is water loss from protonated menthone. The contribution of menthone $\left([\mathrm{M}+\mathrm{H}]^{+}\right)$fragmentation to $\mathrm{m} / \mathrm{z} 137$ can be approximated using the ratio of $\mathrm{m} / \mathrm{z}$ $137: \mathrm{m} / \mathrm{z} 155$ obtained from Figure S1. This shows a ratio of 1.59:1 in favor of the $\mathrm{m} / \mathrm{z}$ 155 ion. Applying this ratio to the data shown in Figure 5 suggests that $\sim 10 \%$ of the $\mathrm{m} / \mathrm{z} 137$ response is generated via this route, and that $\sim 90 \%$ of the $\mathrm{m} / \mathrm{z} 137$ peak is from monoterpene species present in the breath.

Wash out profiles were obtained for $\mathrm{m} / \mathrm{z} 137$ and the menthone $[\mathrm{M}+\mathrm{H}]^{+}$ion ( $m / z$ 155). Two distinct wash out profiles were observed for both ions. In study 1,12 participants saw a rise in the intensity of the exhaled peppermint oil components at 60 min post-ingestion, before decreasing exponentially over the sampling time period. Alternatively, delayed peak intensity was observed in 4 participants showing a maximal ion response at 120 min, reducing to similar levels as the main group by 240 to $360 \mathrm{~min}$. Figure 6 illustrates the emanation and elimination profiles for $\mathrm{m} / \mathrm{z}$ 137 and 155. A comparable rise and fall of the ions, albeit with a delayed 
component, can be clearly depicted for the main set $(n=12)$ and subset $(n=4)$ of participants. The mechanistic underpinning for the presence of alternative profiles is unknown but may be due to variances in capsule breakdown rates in the stomach, or biological variations in molecule absorption/processing. For participants not showing a delayed maximal intensity, ion intensities for $\mathrm{m} / \mathrm{z} 137$ were increased at 60 min $(p=0.008)$ and remained above baseline $(0 \mathrm{~min})$ levels for the entirety of the sampling period ( $p \leq 0.009$ ), with ion intensities of the $m / z 155$ increased at 60 and $120 \min (p \leq 0.020)$ and returning to baseline levels by $240 \min (p>0.05)$. No statistical increases were reported in the delayed ion response group, due to underpowered analyses with $n=4$. Power calculations to report a significant difference at 60 min compared to baseline for a power of $80 \%$ and a $p$ value of $<0.05$ indicate a sample group of $n=13$ would be required. When the two groups were combined, exhaled levels of $\mathrm{m} / \mathrm{z} 137$ remained above baseline values past $360 \mathrm{~min}$ post-ingestion ( $p \leq 0.004$ ) and remained above baseline values for $m / z 155$ until 120 min post-ingestion ( $p$ 's $=0.004$ ) returning to baseline by $240 \mathrm{~min}$ post-ingestion $(p>0.05)$.

Samples taken for up to $10 \mathrm{hrs}$ (600 min, study 2) after ingestion of the peppermint oil capsule showed further decrease of $\mathrm{m} / \mathrm{z} 137$ over time, with median values remaining above baseline throughout (data not shown). Statistically different levels were not observed in this cohort, again due to underpowered analyses with $n=4$. Final elimination of the peppermint oil compounds and a return to baseline values was predicted at approximately 10.5 to $11 \mathrm{hrs}$ post-ingestion. 
Real-time monitoring (study 3)

The continuous real-time measurement of the evolution of peppermint oil from the breath showed an increase in $\mathrm{m} / \mathrm{z} 137$ response after approximately $10-13$ min postingestion. This increase can be attributed to the release of menthone and other monoterpene species from the ingested tablet. Previous work has reported a reduction in exhaled menthone after 5 min of breathing synthetic air, remaining at the reduced levels for up to $30 \mathrm{~min}$ [35]. This continued to increase toward the end of the sampling period (Figure 7). The large intensity peak at 7 min corresponds to involuntary eructation producing a large response of the ion. This occurs due to the breakdown of the capsule in the stomach, followed by an uncontrolled reflux of stomach gases containing high levels of peppermint oil components. Based on the data obtained from the $6 \mathrm{hr}(360 \mathrm{~min})$ experiments, the intensity of the $\mathrm{m} / \mathrm{z} 137$ is expected to further increase before reaching its peak intensity. This observation highlights the suitability of this method for the application of real-time breath analysis and shows the potential for on-line analysis of the metabolism of components released after digestion.

TD-GC-MS wash out (study 4)

A linear calibration was performed on menthone spiked onto TD tubes over a range from 0 to $8 \mathrm{ng}$ on-column mass (OCM) and an excellent linear response was obtained (Figure S2). A washout experiment was performed on a single participant with samples taken at five points ( $t=0,74,174,415$ and $600 \mathrm{~min})$. Figure S3 shows that menthone was observed in the exhaled breath at all sampling time points, including the baseline sample prior to ingestion of the capsule. The pre-ingestion 
sample displayed an OCM of $0.112 \mathrm{ng}$ (corresponding to $56 \mathrm{pg} / \mathrm{L}$ exhaled breath) and increased 7-fold to $0.771 \mathrm{ng} \mathrm{OCM}$ at $74 \mathrm{~min}$ (corresponding to $386 \mathrm{pg} / \mathrm{L}$ exhaled breath). This concentration then dropped over time and reduced to near baseline levels of 0.166 and $0.131 \mathrm{ng} \mathrm{OCM}$ at 415 and $600 \mathrm{~min}$, respectively. An overlay of the extracted ion responses for the menthone fragment ion at $m / z 112$ is shown in Figure S4 to enable visual comparison of the peak area response obtained for menthone at each time point.

Comparison with the obtained calibration indicated that the concentration of menthone in the breath at the 120 min time point was approximately 55 parts per trillion by volume (pptv, see electronic supplementary information for calculations). The menthone $[\mathrm{M}+\mathrm{H}]^{+}$ion at $m / z 155$ is clearly observable in the APCl-MS washout profiles at this point. This observation highlights that the compact mass spectrometer with direct $\mathrm{APCl}$ analysis has great potential as a sensitive in-clinic breath analyzer.

The data obtained from the Venturi pump interface here compares well with the commercially available MS-Nose interface. The MS-Nose is typically used for the analysis of flavor compounds in the breath which has been stated as being in the low ppbv range [19]. A study by Avison [36] compared the quantitative performance of the APCI-MS MS-Nose fitted to a quadrupole mass spectrometer, with an Ionicon PTR-MS system, for 7 different test compounds (2-butanone, E-2-hexenol, hexanoic acid, benzaldehyde, 2,3 DMP, ethyl butyrate and amyl acetate) from the headspace of aqueous solutions. The MS-Nose system obtained limits of detection ranging from 0.1 ppbv for benzaldehyde to 9.1 ppbv for 2-butanone. The demonstrated sensitivity for menthone at 120 min (51 pptv) in this study indicates that the system described here compares favorably with the commercial bench top MS system with the MSNose interface. In addition, the system demonstrated in this report can be interfaced 
into any $\mathrm{APCl}-\mathrm{MS}$ source and does not require permanent modification to the $\mathrm{APCl}$ probe.

\section{Conclusions}

This study shows the first application of a portable APCI-MS instrument to the realtime profiling of a pseudo-metabolite in breath and its comparison with the gold standard GC-MS technique in a parallel experiment. A major limitation restricting clinical breath analysis is the inability to easily transport and set up sensitive instrumentation at the point-of-care. The use of a CMS with a modified APCI inlet demonstrates a portable and rapidly deployable answer to overcome this challenge. The combination of the vapor introduction interface with the APCI-MS is shown to be capable of detecting breath metabolites, such as acetone, with good levels of sensitivity. The introduction of an artificial change in the breath profile to act as pseudo-biomarker was accomplished by ingestion of a peppermint oil capsule. The data obtained from this experiment illustrates that this system can detect changes in exhaled breath profiles both in real-time and across an extended time period, with differences observed in breath profiles for up to $10 \mathrm{hrs}$ after ingestion of the peppermint oil capsule. Comparative data obtained by TD-GC-MS suggests that the APCI-MS approach using the CMS is highly sensitive and capable of detecting peppermint oil compounds at levels in the low pptv range. The modified instrumentation was demonstrated as capable for measurement in real-time through the continuous monitoring of an induced metabolic change in the breath, in a manner similar to flavor release experiments reported by Linforth and Taylor [19-21].

These data show that direct, high-sensitivity measurements from breath are possible using a portable mass spectrometer with a simple and straightforward modification to the $\mathrm{APCl}$ gas inlet line, using the standard $\mathrm{APCl}$ source. The 
instrumentation used in this study is low cost, lightweight and the results obtained show that trace levels of a VOC in the breath can be detected, highlighting its suitability for metabolite monitoring. The APCI inlet modification described in this report can be installed/removed as required, allowing for the instrumentation to be employed for multiple sample mediums at the discretion of the analyst. Furthermore, the combination of breath analysis with the portable mass spectrometer has the potential to be used as a deployable instrument (i.e. on a portable trolley) which can be quickly setup in a clinical research environment, or at a remote location and used to carry out in-situ breath tests. 


\section{Future Perspective:}

Future development of compact mass spectrometers poses exciting possibilities in the rapid on-line analysis of health and disease. On-line analysis has the potential to monitor targeted breath metabolites in a continuous manner that can be utilized for health observations in a clinical setting. Therefore, the completion of extended experiments similar to that described in this report would be beneficial. It is also of great interest to be able to accurately quantitate exhaled metabolites using this technique. In order to overcome complex ion chemistries in the APCI source, future developments incorporating stable isotope labelled internal standards are required. With commercialization of exhaled breath sampling devices coupled to purpose built portable compact mass spectrometer units, the ability to sample patients at the pointof-care is a real possibility. Furthermore, the technology is perfectly amenable to be adapted for use away from disease scenarios such as rapid assessment of exhaled breath profiles for everyday life or sporting situations. Perhaps in 10 years from now we will see these devices used to assess general health status/diagnose diseaseonset in public hospitals and/or general practitioners' surgeries.

\section{Executive Summary:}

\section{Background}

- Analysis of exhaled breath volatiles has gained interest in recent years as a method to assess biological processes.

- The ability to miniaturize and simplify analytical instrumentation is desirable for on-line, point-of-care analysis. 


\section{Experimental}

- An in-house designed interface allowed for the coupling of a full-face breath mask to an Advion Expression compact mass spectrometer.

- Volunteers provided exhaled breath samples prior to and on several occasions post-ingestion of a commercially available peppermint oil capsule.

\section{Results \& Discussion}

- Ions related to the breakdown of the peppermint capsule were detected in elevated levels at $60-120$ min post-ingestion.

- A wash-out profile of the peppermint oil related ions was observed and menthone was detectable at levels above baseline at 360 min post-ingestion.

- Detectable levels were comparable to previously validated GC-MS methods in the range of parts per trillion by volume.

\section{Conclusion}

- A straightforward modification using the standard $\mathrm{APCl}$ source allowed for high sensitivity measurements of exhaled breath volatiles on a portable compact mass spectrometer, with potential use in clinical and other nonlaboratory based scenarios. 


\section{References}

1 Beck O, Stephanson N, Sandqvist S, Franck J. Detection of drugs of abuse in exhaled breath from users following recovery from intoxication. J. Anal. Toxicol. 36(9), 638-646 (2012).

2 Déléris I, Saint-Eve A, Sémon E et al. Comparison of direct mass spectrometry methods for the on-line analysis of volatile compounds in foods. J. Mass Spectrom. 48(5), 594-607 (2013).

3 Basanta M, Jarvis RM, Xu Y et al. Non-invasive metabolomic analysis of breath using differential mobility spectrometry in patients with chronic obstructive pulmonary disease and healthy smokers. Analyst 135(2), 315-320 (2010).

4 Fens N, van der Schee MP, Brinkman P, Sterk PJ. Exhaled breath analysis by electronic nose in airways disease. Established issues and key questions. Clin. Exp. Allergy 43(7), 705-715 (2013).

5 Laakso O1, Haapala M, Jaakkola P et al. The use of low-resolution FT-IR spectroscopy for the analysis of alcohols in breath. J. Anal. Toxicol. 24(4), 250-256 (2000).

$6 \mathrm{Kim} \mathrm{KH}$, Jahan SA, Kabir E. A review of breath analysis for diagnosis of human health, TrAC Trends Anal. Chem. 33, 1-8 (2012). 
7 Turner MA, Bandelow S, Edwards L et al. The effect of a paced auditory serial addition test (PASAT) intervention on the profile of volatile organic compounds in human breath: a pilot study. J. Breath Res. 7(1), 017102 (2013).

8 Trefz P, Rösner L, Hein D, Schubert JK, Miekisch W. Evaluation of needle trap micro-extraction and automatic alveolar sampling for point-of-care breath analysis. Anal. Bioanal. Chem. 405(10) 3105-3115 (2013).

*Demonstrates the use of in-line preconcentration for in-situ breath analysis.

9 Beauchamp J, Herbig J, Gutmann R, Hansel A. On the use of Tedlar ${ }^{\circledR}$ bags for breath-gas sampling and analysis. J. Breath Res. 2(4), 046001 (2008).

10 Trefz $\mathrm{P}$, Schmidt M, Oertel $\mathrm{P}$ et al. Continuous real time breath gas monitoring in the clinical environment by proton-transfer-reaction-time-of-flight-mass spectrometry. Anal. Chem. 85(21), 10321-10329 (2013).

*This article is a demonstration of the capability of proton transfer mass spectrometry for real-time breath analysis.

11 Smith D, Španěl P, Herbig J, Beauchamp J. Mass spectrometry for real-time quantitative breath analysis. J. Breath Res. 8(2), 027101 (2014).

12 Španěl P, Smith D. Progress in SIFT-MS: breath analysis and other applications. Mass Spectrom. Rev. 30(2), 236-267 (2011). 
13 Spesyvyi A, Smith D, Španěl P. Selected Ion Flow-Drift Tube Mass Spectrometry: Quantification of Volatile Compounds in Air and Breath. Anal. Chem. 87(24), 1215112160 (2015).

14 Chen H, Venter A, Cooks RG. Extractive electrospray ionization for direct analysis of undiluted urine, milk and other complex mixtures without sample preparation. Chem. Comm. 19, 2042-2044 (2006).

15 Reynolds JC, Blackburn GJ, Guallar-Hoyas C et al. Detection of volatile organic compounds in breath using thermal desorption electrospray ionization-ion mobilitymass spectrometry. Anal. Chem. 82(5) 2139-2144 (2010).

16 Reynolds JC, Jimoh MA, Guallar-Hoyas C, Creaser CS, Siddiqui S, Thomas CL. Analysis of human breath samples using a modified thermal desorption - gas chromatography electrospray ionization interface. J. Breath Res. 8(3), 037105 (2014).

17 Chen $\mathrm{H}$, Wortmann A, Zhang $\mathrm{W}$, Zenobi R. Rapid In Vivo Fingerprinting of Nonvolatile Compounds in Breath by Extractive Electrospray Ionization Quadrupole Time-of-Flight Mass Spectrometry. Angew. Chem. Int. Ed. Engl. 46(4) 580-583 (2007).

*This article demonstrates that extractive electrospray can be used for high sensitivity measurements of volatiles in breath samples. 
18 Ding J, Yang S, Liang D et al. Development of extractive electrospray ionization ion trap mass spectrometry for in-vivo breath analysis. Analyst 134(10) 2040-2050 (2009).

19 Taylor AJ, Linforth RST, Harvey BA, Blake A. Atmospheric pressure chemical ionisation mass spectrometry for in vivo analysis of volatile flavour release. Food Chem. 71, 327-338 (2000).

${ }^{\star \star}$ This paper demonstrates the use of a Venturi inlet to sample volatiles into an APCI ion source.

20 Taylor AJ, Linforth RST. Direct mass spectrometry of complex volatile and nonvolatile flavour mixtures. Int. J. Mass Spectrom. 223-224, 179-191 (2003).

21 Jublot L, Linforth RST, Taylor AJ. Direct atmospheric pressure chemical ionisation ion trap mass spectrometry for aroma analysis: Speed, sensitivity and resolution of isobaric compounds. Int. J. Mass Spectrom. 243, 267-277 (2005)

$22 \mathrm{Li} \mathrm{Y}$. Applications of a confined DART (direct analysis in real time) ion source for online in vivo analysis of human breath. Anal. Methods 5, 6933-6940 (2013).

23 Linforth RST, Taylor AJ. Apparatus and methods for the analysis of trace constituents in gases. US5869344 A (1999).

**This is the patent for a commercial ion source using a Venturi inlet to sample volatiles into an APCl ion source. 
24 Berchtold C, Meier L, Zenobi R. Evaluation of extractive electrospray ionisation and atmospheric pressure chemical ionisation for the detection of narcotics in breath. Int. J. Mass Spectrom. 299, 145-150 (2011).

25 Browne DL, Wright S, Deadman BJ et al. Continuous flow reaction monitoring using an on-line miniature mass spectrometer. Rapid Commun. Mass Spectrom. 26(17), 1999-2010 (2012).

26 Joshi A, Bhobe M, Sattarkar A. Phytochemical investigation of the roots ofGrewia microcosLinn. J. Chem. Pharm. Res. 5(7), 80-87 (2013).

27 Beauchamp J, Kirsch F, Buettner A. Real-time breath gas analysis for pharmacokinetics: monitoring exhaled breath by on-line proton-transfer-reaction mass spectrometry after ingestion of eucalyptol-containing capsules. J. Breath Res. 4(2), 026006 (2010).

28 Ruzsanyi V. Ion mobility spectrometry for pharmacokinetic studies--exemplary application. J. Breath Res. 7(4), 046008 (2013).

29 Basanta M, Koimtzis T, Singh D, Wilson I, Thomas CL. An adaptive breath sampler for use with human subjects with an impaired respiratory function. Analyst 132(2), 153-163 (2007).

*This paper describes a highly sensitive GC-MS method for the analysis of trace volatiles in exhaled breath 
30 Wang Z, Wang C. Is breath acetone a biomarker of diabetes? A historical review on breath acetone measurements. J. Breath Res. 7(3), 037109 (2013).

31 Smith D, Španěl P, Davies S. Trace gases in breath of healthy volunteers when fasting and after a protein-calorie meal: a preliminary study. J. Appl. Physiol. 87(5), 1584-1588 (1999).

32 Wang C, Mbi A, Shepherd M. A study on breath acetone in diabetic patients using a cavity ringdown breath analyzer: exploring correlations of breath acetone with blood glucose and glycohemoglobin A1C. IEEE Sensors J. 10(1), 54-63 (2010).

33 Jiang MH, Yang L, Zhu L, Piao JH, Jiang JG. Comparative GC/MS analysis of essential oils extracted by 3 methods from the bud of Citrus aurantium L. var. amara Engl. J. Food Sci. 76(9), C1219-1225 (2011).

34 Steeghs MML, Crespo E, Harren FJM. Collision induced dissociation study of 10 monoterpenes for identification in trace gas measurements using the newly developed proton-transfer reaction ion trap mass spectrometer. Int. J. Mass Spectrom. 263(2-3), 204-212 (2007).

35 Maurer F, Wolf A, Fink T et al. Wash-out of ambient air contaminations for breath measurements. J. Breath Res. 8(2), 024107 (2014).

*This experiment showed the reduction of exhaled menthone after the breathing of synthetic air. 
36 Avison SJ. Real-time flavor analysis: optimization of a proton-transfer-mass spectrometer and comparison with an atmospheric pressure chemical ionization mass spectrometer with an MS-nose interface. J. Agric. Food Chem. 61(9), 20702076 (2013). 


\section{Figure Captions}

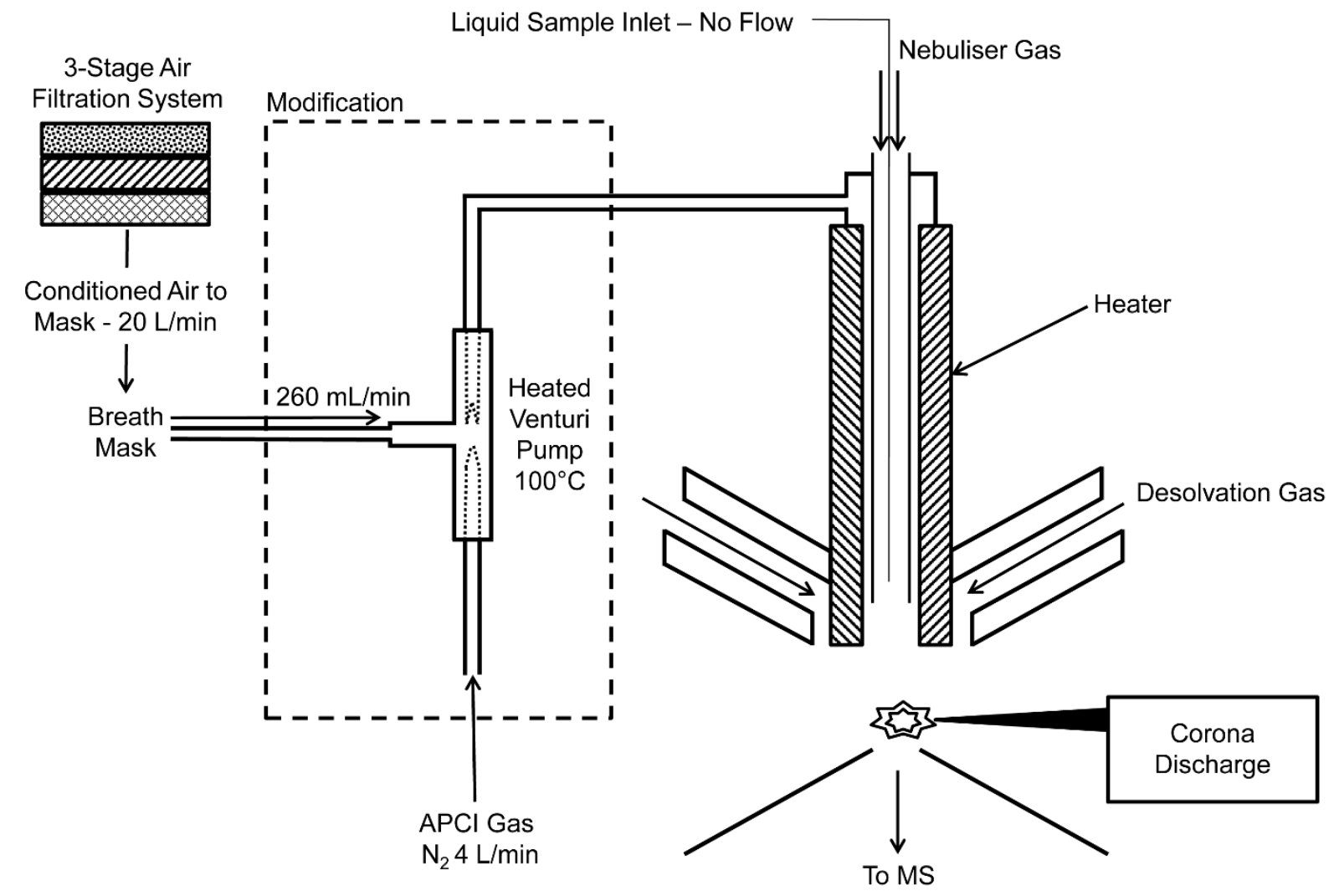

Figure 1. Schematic drawing illustrating the modification to the $\mathrm{APCl}$ gas line to incorporate a heated Venturi pump and full face breathing mask to allow analysis of exhaled gases via APCI-MS using a compact mass spectrometer.

Note: $\mathrm{APCI}-\mathrm{MS}=$ atmospheric pressure chemical ionization-mass spectrometry 


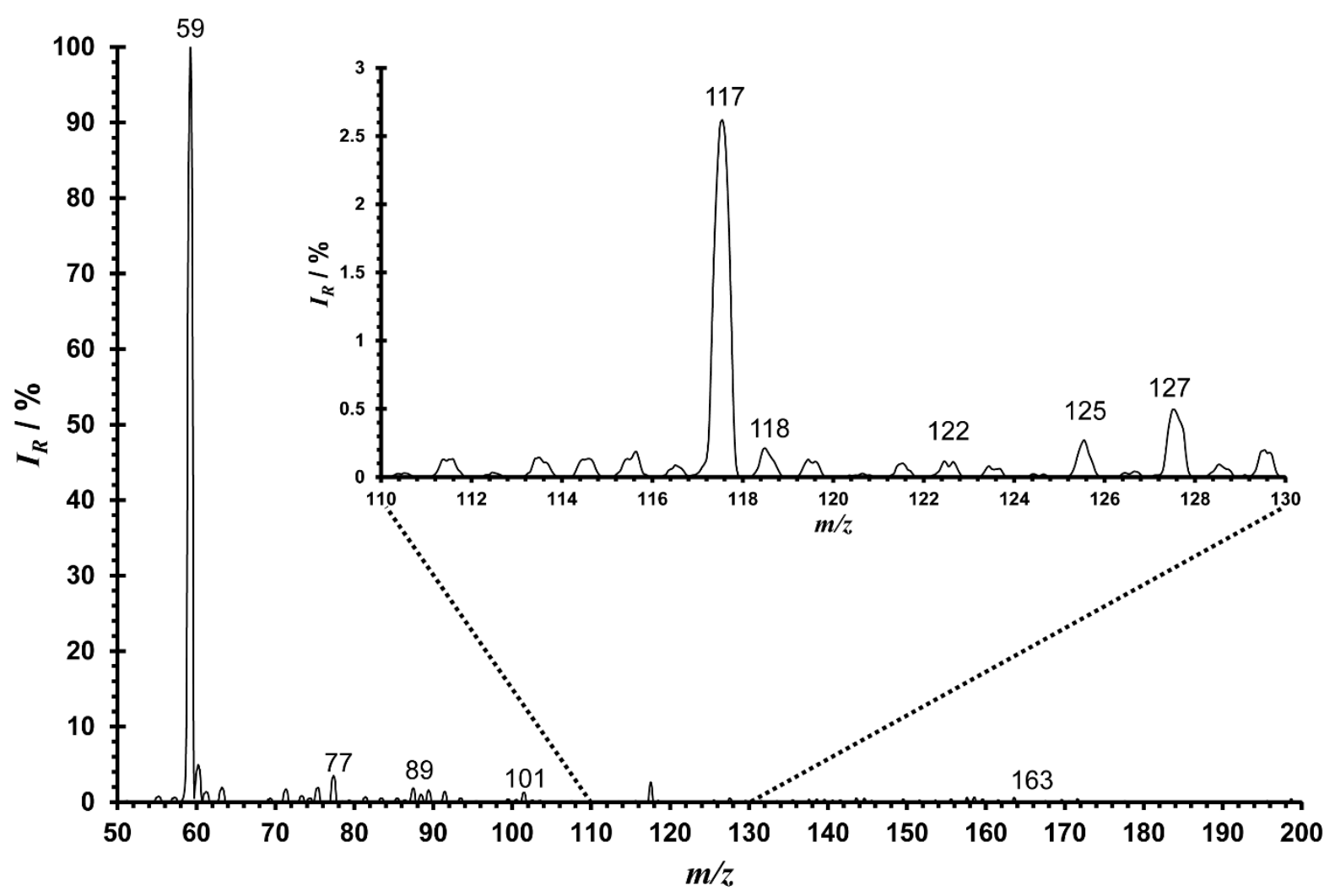

Figure 2. Averaged APCI-MS mass spectrum across a 3 min sampling period for one participant prior to ingestion of the peppermint oil capsule.

Note: $\mathrm{APCl}-\mathrm{MS}=$ atmospheric pressure chemical ionization-mass spectrometry; $I_{R}=$ relative intensity; $m / z=$ mass to charge ratio 


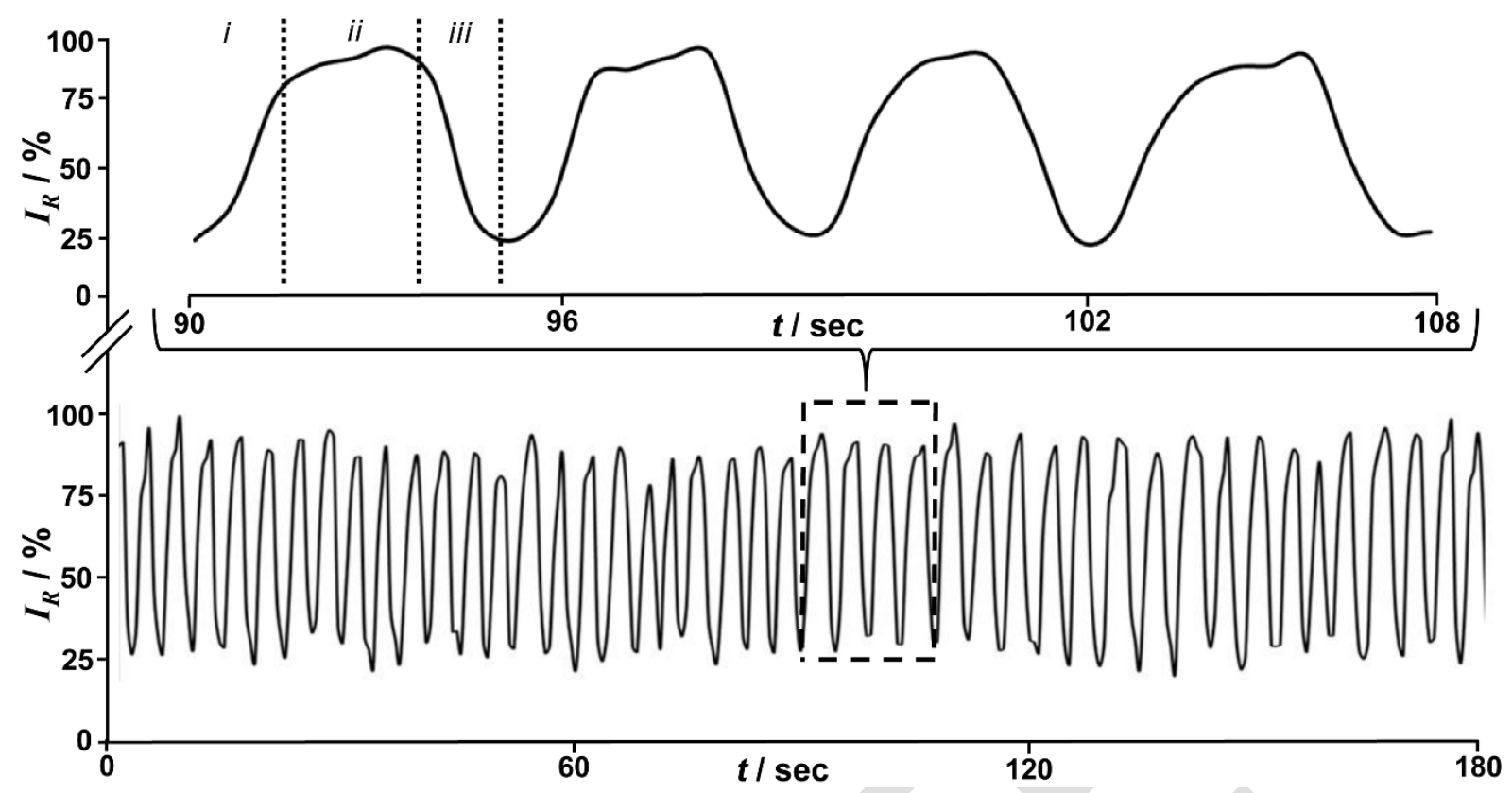

Figure 3. Example total ion trace for one participant over a 3 min sampling period (bottom) with expanded view of four breaths (top) to show the total ion response corresponding to (i) the increased exhalation at the beginning of the breath, (ii) steady-state exhalation during the middle portion of breath and (iii) the cessation of exhalation and onset of inhalation toward the final stage of the breath.

Note: $I_{R}=$ relative intensity; $t=$ time 


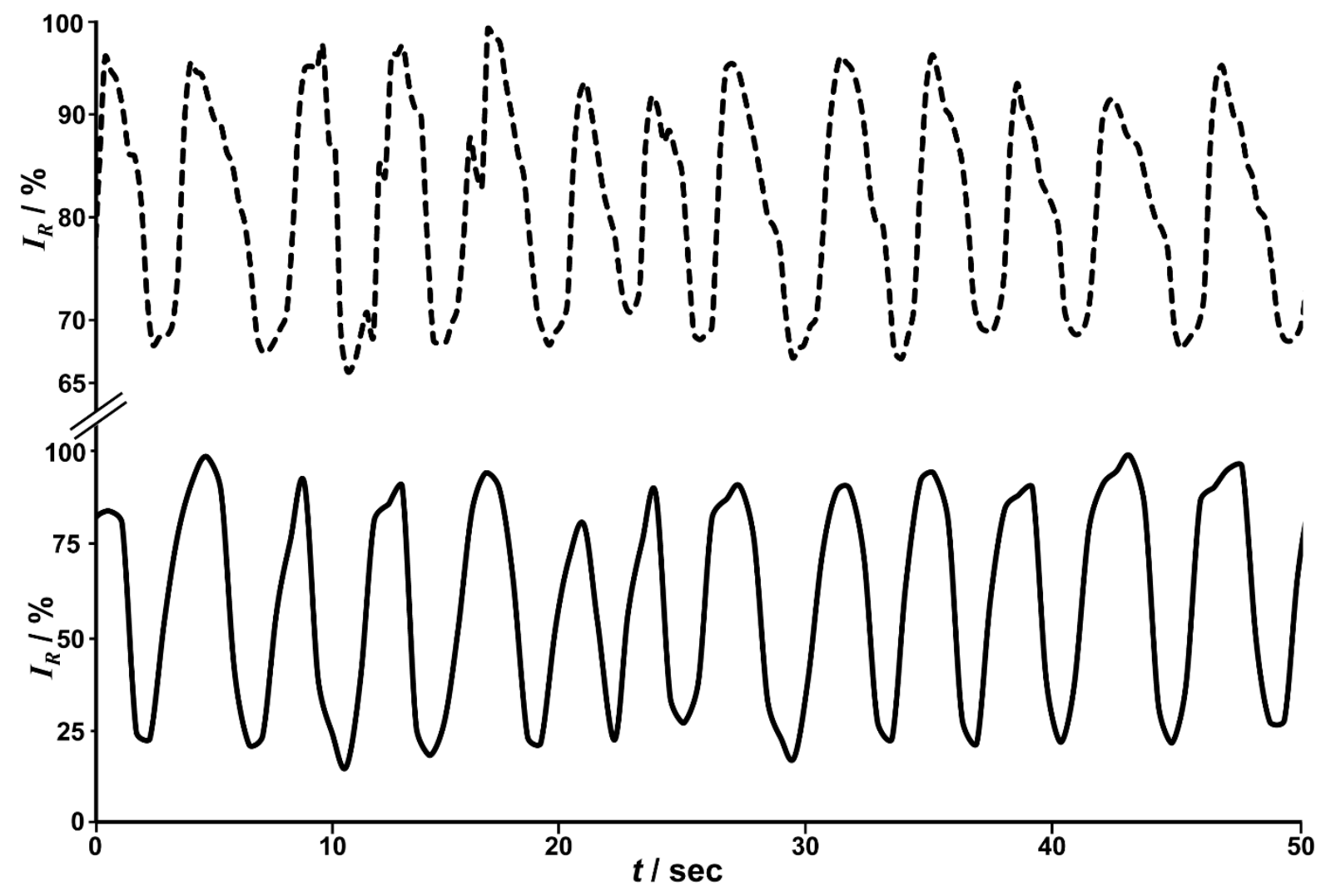

Figure 4. Example pressure trace of the full face breathing mask (top - dotted line) and the time-matched total ion response from the compact mass spectrometer (bottom - solid line). Each peak corresponds to one breath and shows a matching response of breathing profile from both sampling modalities.

Note: $I_{R}=$ relative intensity; $t=$ time 


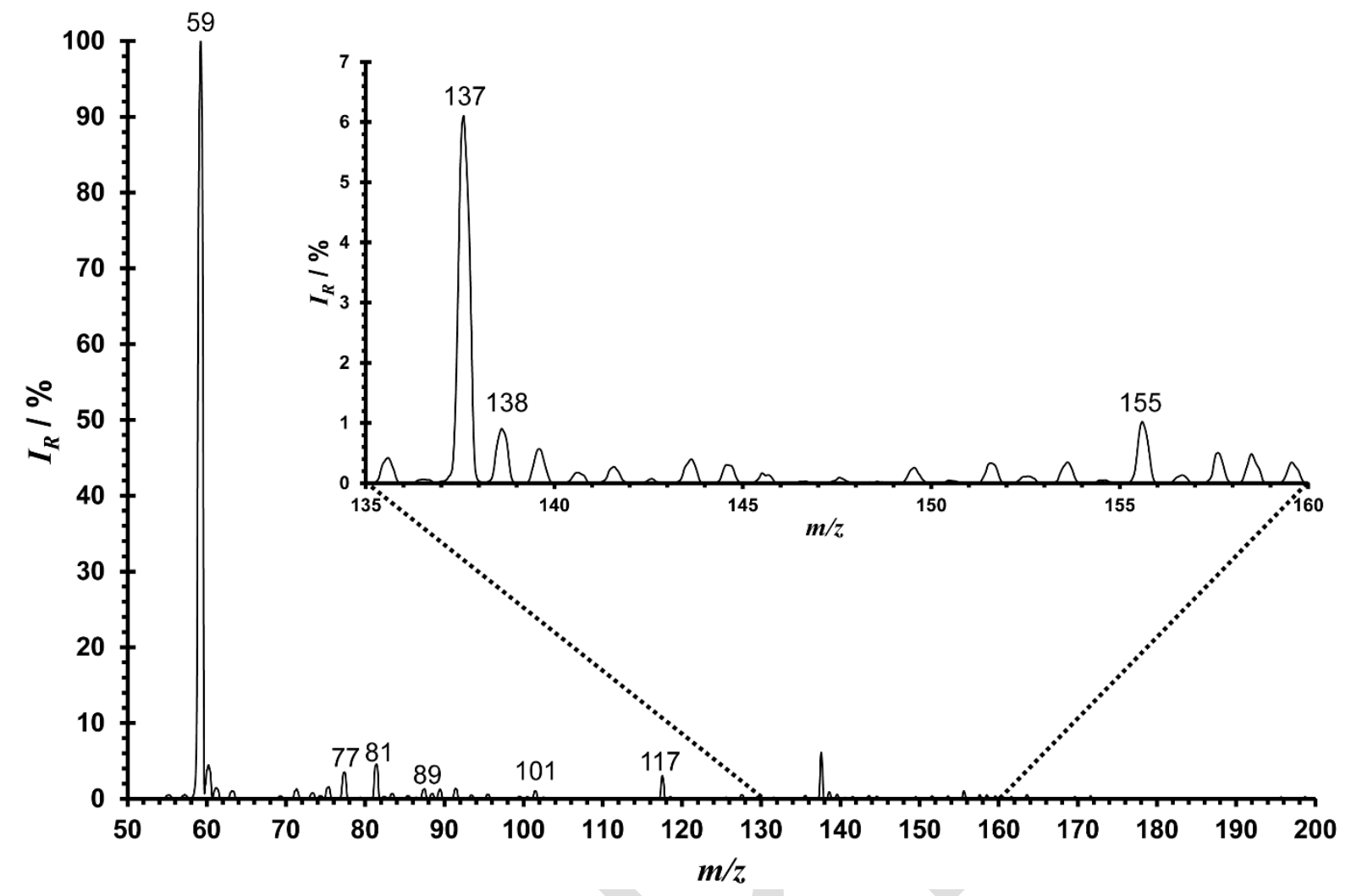

Figure 5. Averaged APCI-MS mass spectrum across a 3 min sampling period for one participant at 60 min post-ingestion of the peppermint oil capsule.

Note: $\mathrm{APCI}-\mathrm{MS}=$ atmospheric pressure chemical ionization-mass spectrometry; $I_{R}=$ relative intensity; $m / z=$ mass to charge ratio 


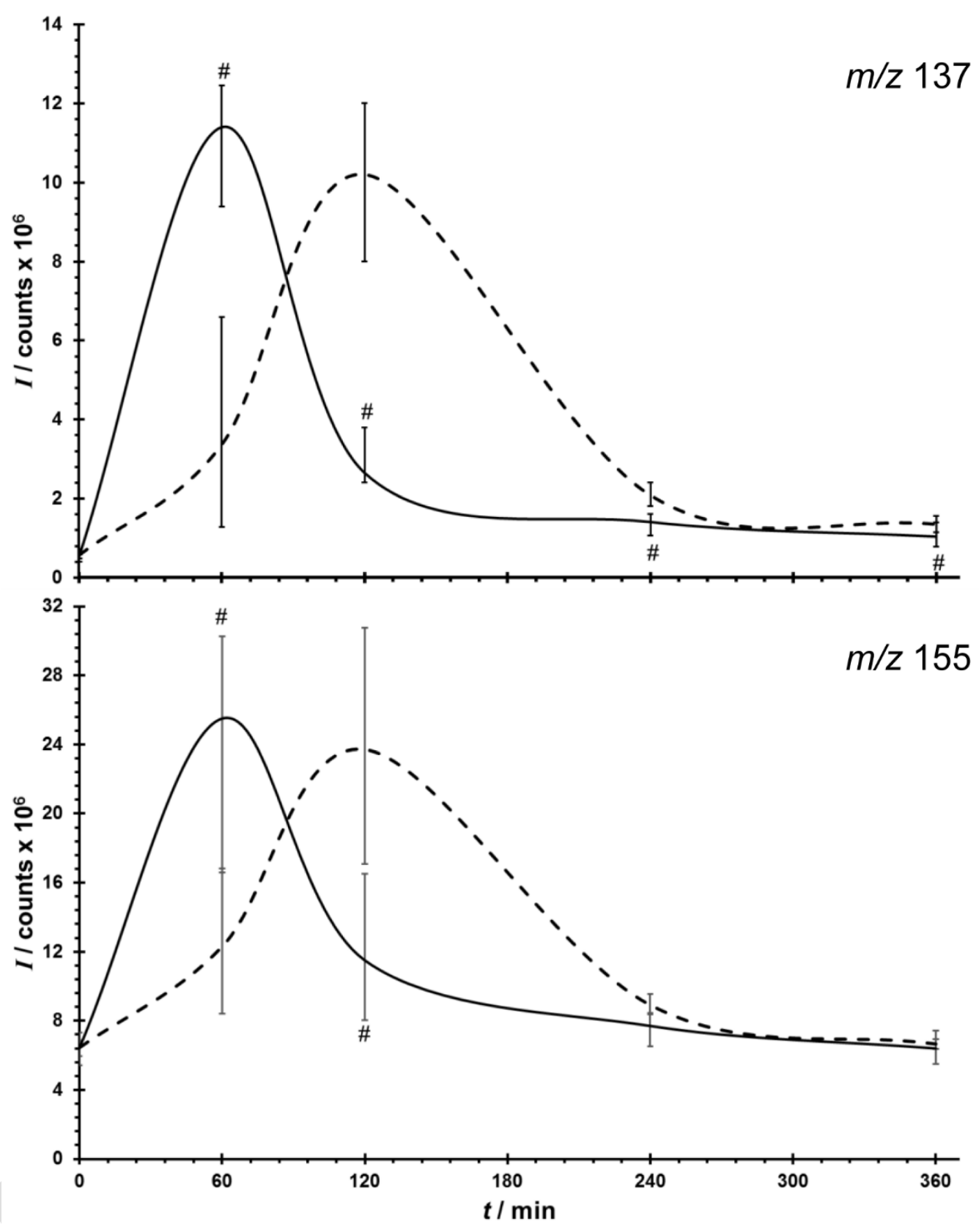

Figure 6. Extracted ion response for all participants stratified by common (solid line, $n=12$ ) and delayed (dashed lined, $n=4$ ) maximal intensities of $m / z 137$ (top) and $m / z$ 155 (bottom) from prior to and up to 360 min post-ingestion of the peppermint oil capsule. Plotted points refer to the median value and error bars to the interquartile range. \# $\mathrm{p} \leq 0.020$

Note: $I=$ intensity; $t=$ time 


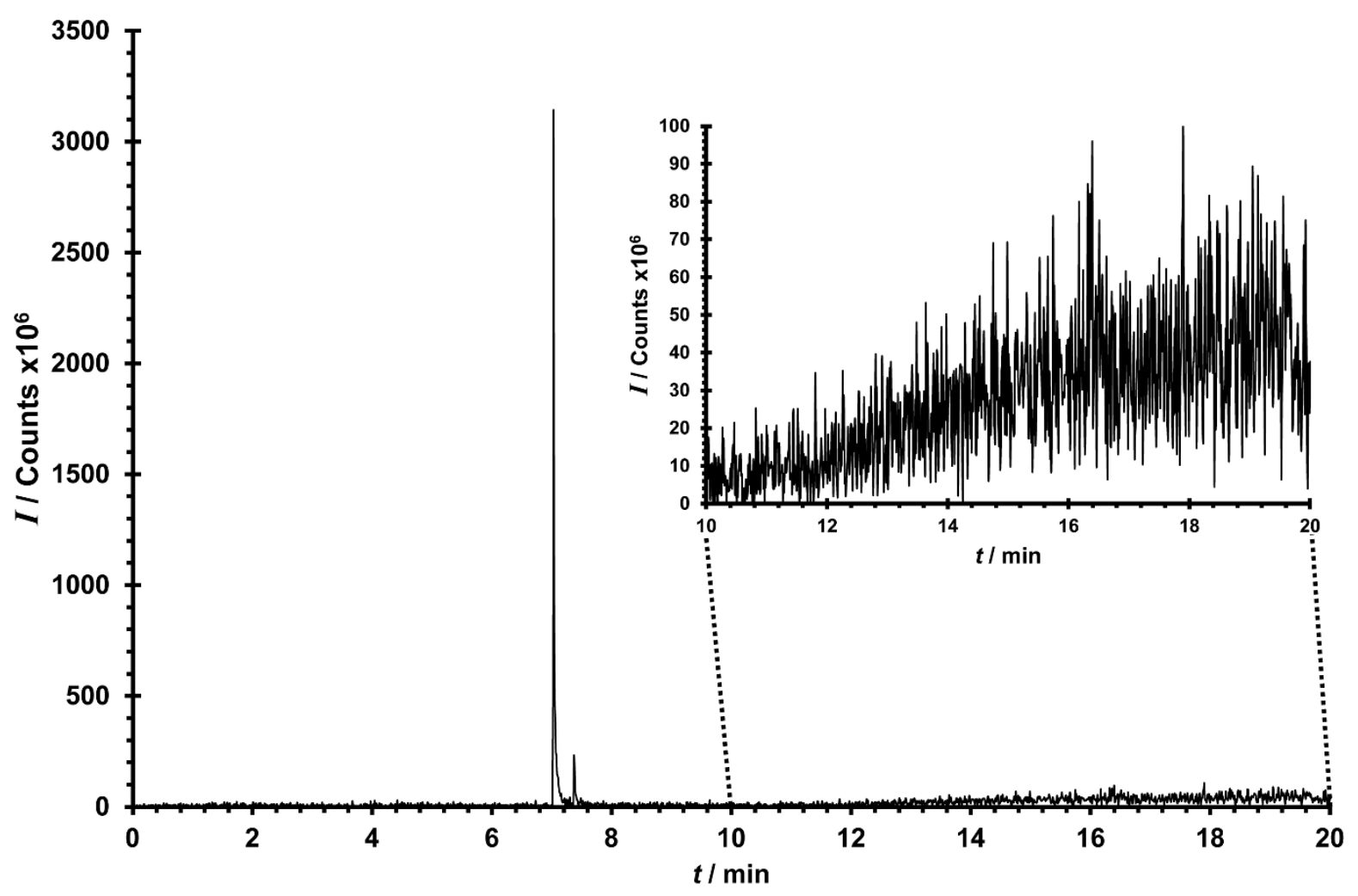

Figure 7. Extracted ion trace for $\mathrm{m} / \mathrm{z} 137$ in one participant for 20 min immediately post-ingestion of the peppermint oil capsule. Large peak intensity seen at $7 \mathrm{~min}$ corresponds to involuntary eructation. The inset shows the steady increase in $\mathrm{m} / \mathrm{z}$ 137 observed between 10 to 20 min.

Note: $I=$ intensity; $t=$ time 


\section{Electronic Supplementary Material}

Real-time monitoring of exhaled volatiles using atmospheric pressure chemical ionization on a compact mass spectrometer

Heaney LM, Ruszkiewicz DM, Arthur KL, Hadjithekli A, Aldcroft C, Lindley MR, Thomas CLP, Turner MA, Reynolds JC. 


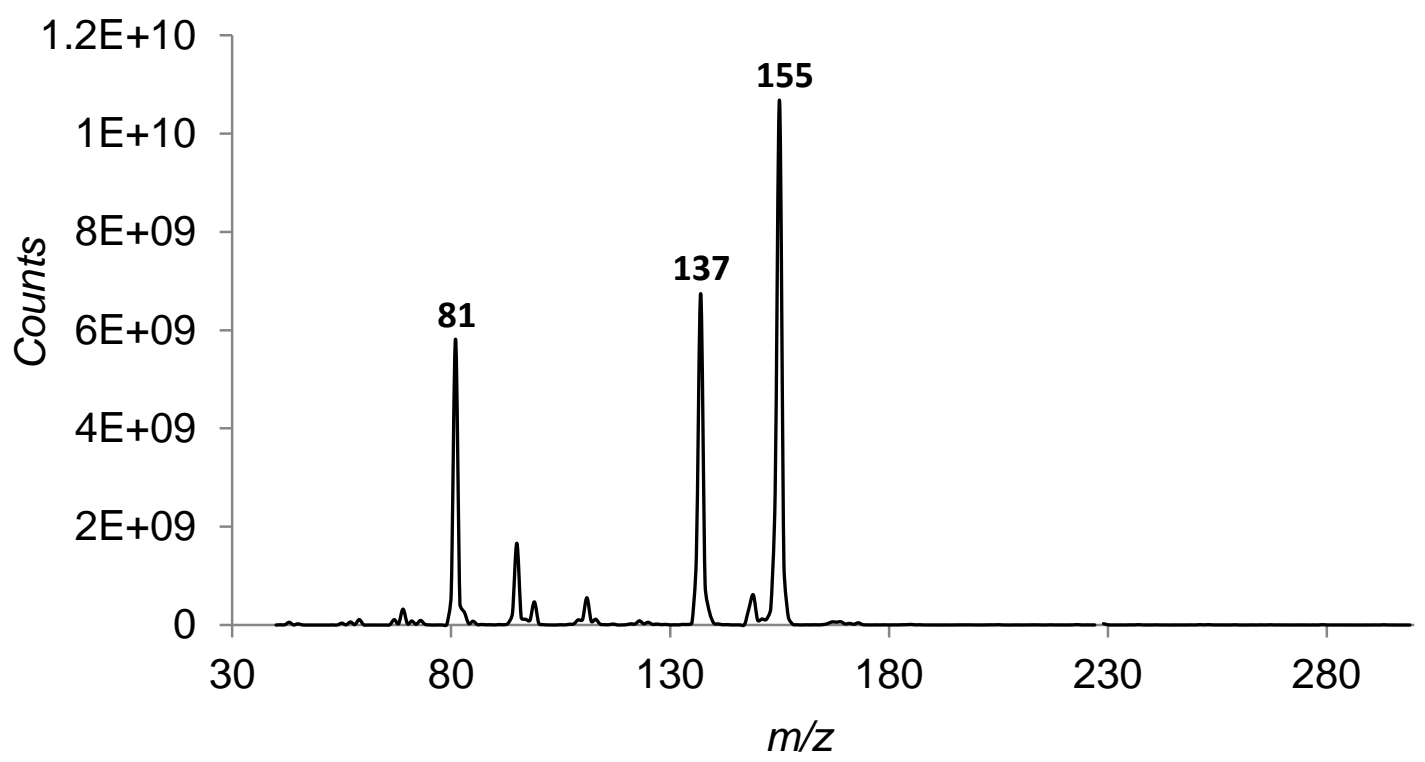

Figure S1. APCI-MS spectrum of the volatile headspace from a $1.0 \%$ menthone solution in HPLC grade water. 


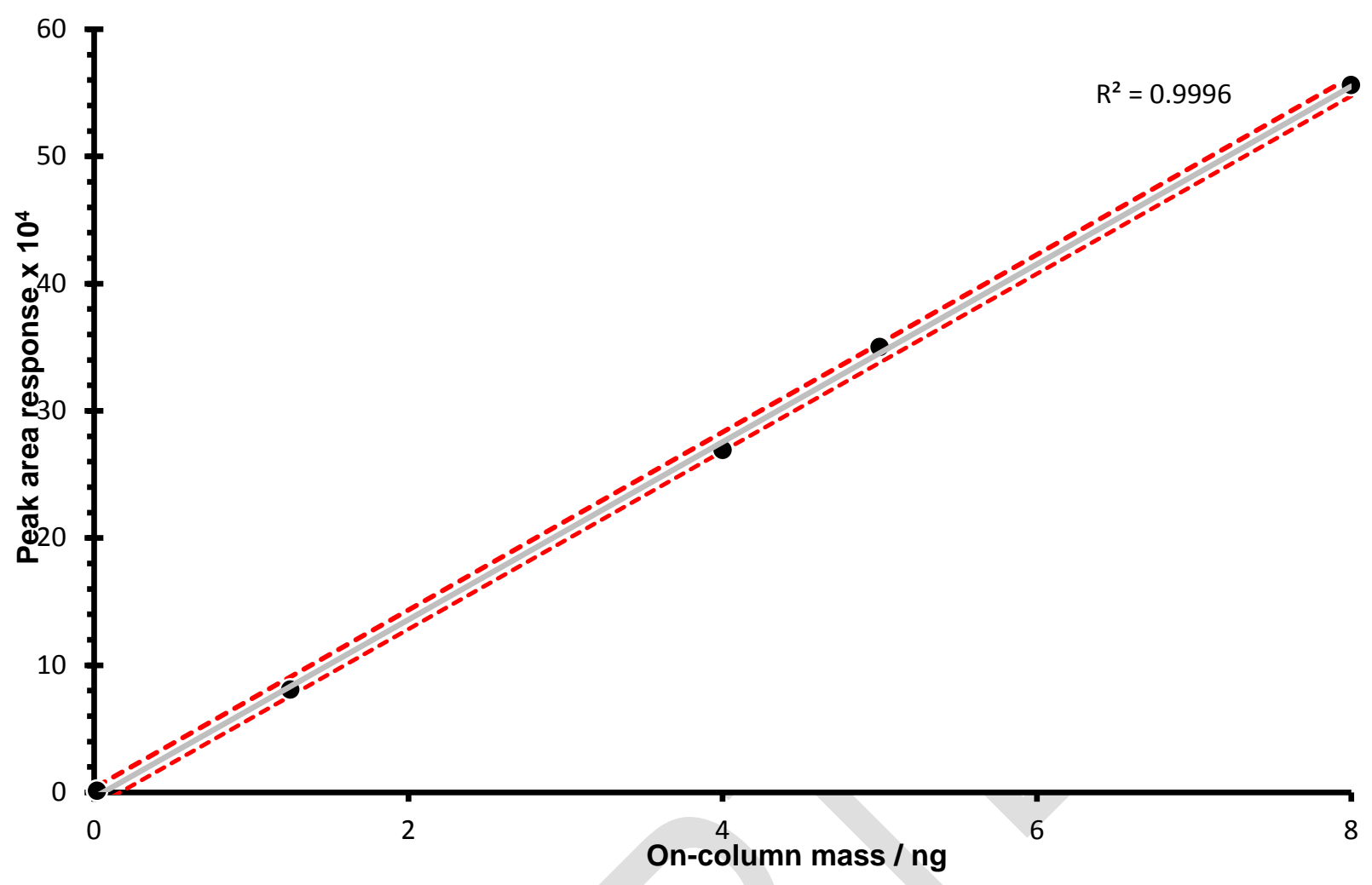

Figure S2. External calibration for the $\mathrm{m} / \mathrm{z} 112$ fragment ion of menthone from the GC-MS analysis of liquid standards spiked on Tenax/Carbograph TD tubes displaying 95\% confidence limits (dotted red lines). 


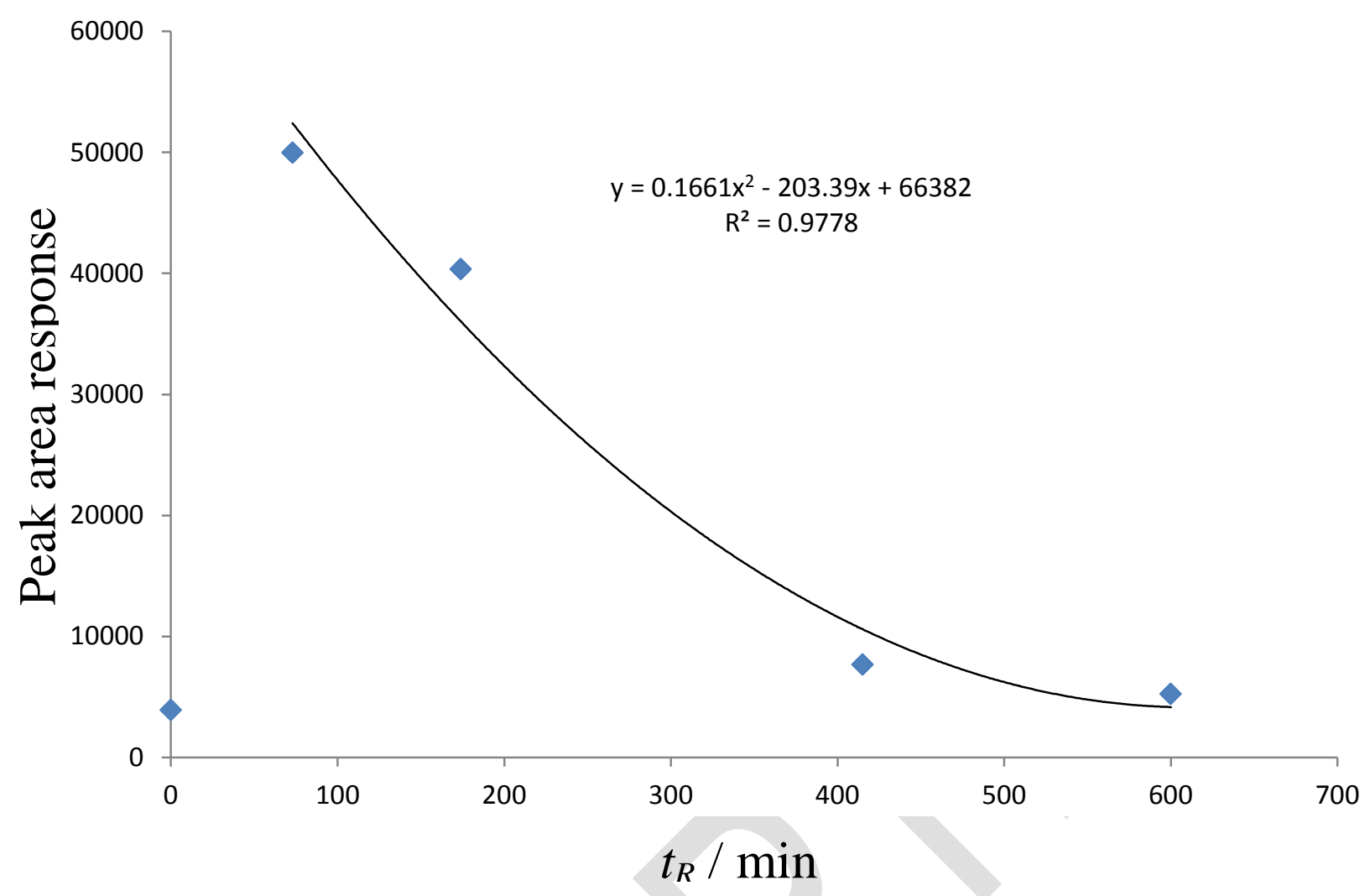

Figure S3. Graph showing the intensity of the $\mathrm{m} / \mathrm{z} 112$ ion (menthone fragment) obtained by TD-GC-MS against time over a 600 min time course post-ingestion of a peppermint oil capsule. 


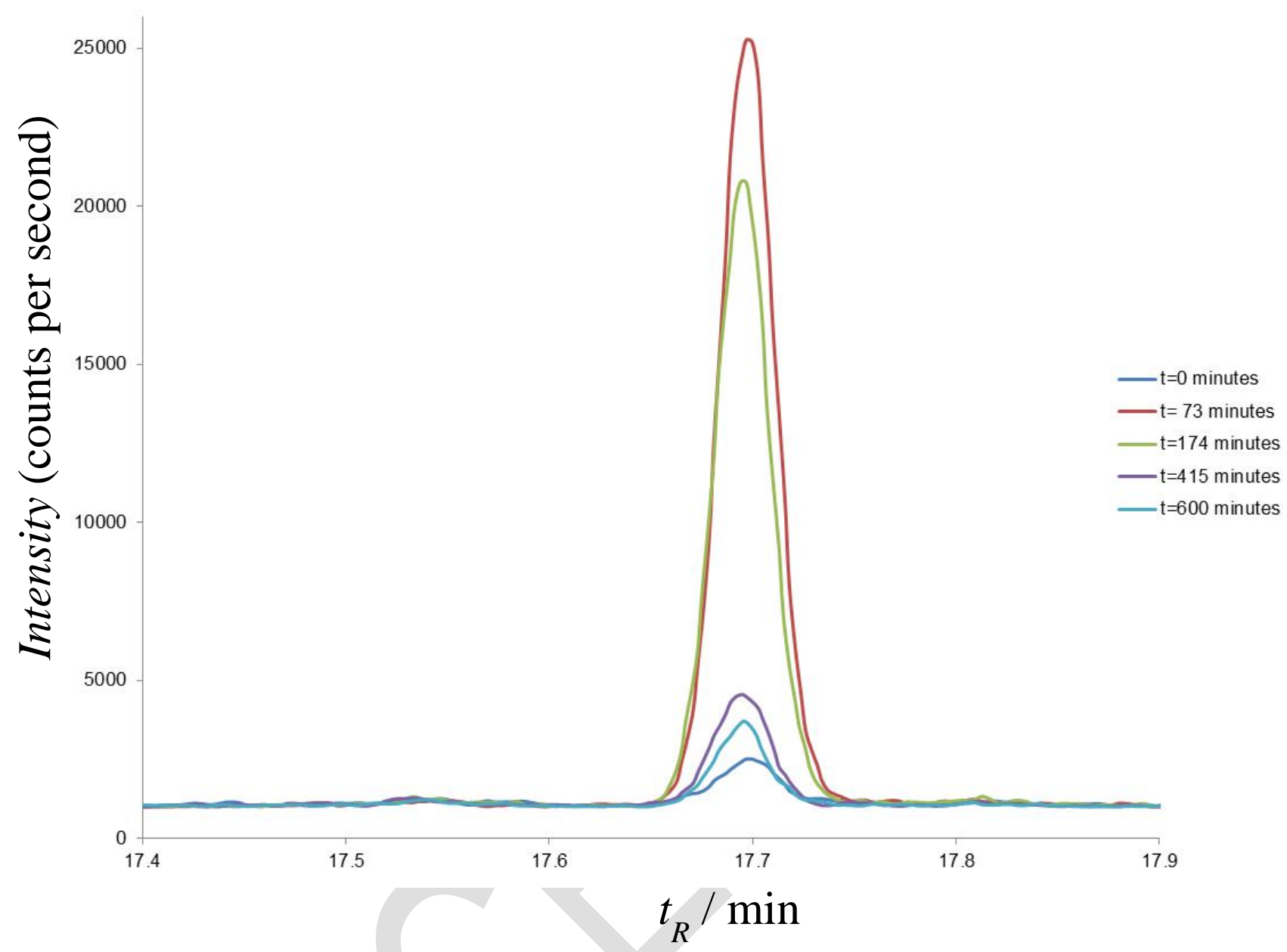

Figure S4. Overlaid TD-GC-MS extracted ion traces for the $m / z 112$ fragment ion of menthone from each of the 5 sampling points of the 600 min washout experiment. 


\section{Calculations}

From Figure S2 at 120 minutes the peak area response for $m / z 112$ is calculated by:

$y=0.1661 x^{2}-203.39 x+66382$

$y=\left(0.1661 * 120^{2}\right)-(203.30 * 120)+66382$

$y=2391.84-24396+66382$

Peak area response at 120 minutes $=44378 \mathrm{cps}$

On-column mass (OCM) is found by extrapolating this from the calibration graph (Figure S2) (rearranging $\mathrm{y}=\mathrm{m} x+\mathrm{c}$ ) gives:

$44378+3950.9 / 69885$

$\mathrm{OCM}=0.692 \mathrm{ng}$

2 litres of breath were collected therefore the concentration of menthone per litre was $0.346 \mathrm{ng} / \mathrm{L}$

Conversion to ppbv was accomplished using the following equation.

Concentration in $\mathrm{ppbv}=($ concentration in $\mathrm{ng} / \mathrm{L} \times 24.45) /$ relative molecular mass Please note:

$1 \mathrm{M}$ of gas expands to fill $24.45 \mathrm{~L}$ at normal temperature $\left(25^{\circ} \mathrm{C}\right)$ and pressure $(1$ atm)

$\mathrm{RMM}$ of menthone $=154 \mathrm{amu}$

Concentration ppbv $=(0.346 \times 24.45) / 154$

$=0.0549 \mathrm{ppbv}=54.9 \mathrm{pptv}$

Menthone concentration at 120 minutes $=54.9 \mathrm{pptv}$ 